\title{
Çalışanlara Uygulanan Mobbing, Psikolojik Şiddet ve İntihar Eğilimlerinin Sosyo Ekonomik Etkileri
}

\author{
Ayla Avcı \\ Istanbul Sabahattin Zaim Üniversitesi Sosyal Bilimler Enstitüsü Işletme Bölümü \\ ORCID: A.AvcI (0000-0002-1871-4090)
}

\begin{abstract}
Özet
Bireylerin günlük yaşamda yaşadıkları olumsuzluklar, fiziksel ve ruhsal olarak hastalıklar yaşamasına ve dolayısıyla en nihayetinde intihar gibi trajik sonların ortaya çıkmasına sebep olmaktadır. Özellikle yirmibirinci yüzyılın en önemli problemi iş yerlerinde yaşanan, çalıșanlar ve üst-ast arasında meydana gelen psikolojik şiddet ve mobbing uygulamaları bu istenmeyen ve üzücü durumlara en büyük etkendir. Çalıșmada mobbing ve psikolojik şiddet unsurları incelenerek çalışanlarda yaşanan intihar olaylarındaki artışın önlenmesi için gerekli çözüm üretme yöntemleri irdelenmiştir.
\end{abstract}

Anahtar Kelimeler: Travma, İntihar, Mobbing, Psikolojik Şiddet.

\section{The Effects of Mobbing and Psychological Violence Applied to Employee}

\begin{abstract}
The negativities experienced by individuals in daily life cause pyhsical and mental illneses and ultimately lead to tragic endings such as suicide. The most important problem especially in thetwenty-first century is the psychological violence and mobbing practices that occur in the workplace between the employees and the supra-ast, which is the biggest factor in these undesirable and sad situations. In this study, mobbing and psychological violence examined and solution methods to prevent the increase of suicide incidents were investigated.
\end{abstract}

Keywords: Trauma, Suicide, Mobbing, Psychological Violence.

\section{Gíriş}

Kurumların en önemli başarısı, çalışanlar ve yöneticiler arasında amaç ve fikir birliği uyumu sağlanarak geleceğe yönelik sürdürülebilirlik sağlamaktır. Ancak örgüt içi çıkar çatışmaları ve iş görenler arasında oluşan rol belirsizliği ya da kişisel hırslar bireylerin kendi içlerinde ve aşamayacakları durumlar ortaya çıkararak ruhsal ve fiziksel birtakım rahatsızlıklar yaşanmasına neden olmaktadır. Çalışma ortamında üstün asta ya da çalışan ve çalışan arasında yaşanan psikolojik şiddet ve mobbing uygulamaları bireylerin ya kendi içlerine kapanarak ruhsal sorunlar yaşamalarına ya da dışa yansıttıklarında ise örgütte dişlanmayla sonuçlanacak ileri sorunların ortaya çıkmasına neden olmaktadır.

ABD'li araştırmacılara göre bireylerin çalıştıkları iş kollarına göre intihar oranlarında artış yaşanmaktadır. Yapı-

*Yazışma Adresi / Address for Correspondence:

Ayla Avcı, Email: avcayla@gmail.com

Geliş Tarihi / Received Date: 06.07.2019

Kabul Tarihi / Accepted Date: 08.08.2019

Doi: $10.26701 /$ uad. 588044 lan araștırmada 2000-2016 yılları arasında erkeklerde en yüksek, inşaat ve madencilik alanında, kadınlarda ise en yüksek intihar oranı, sanat, tasarım, spor ve medya çalıŞanları arasında görülmektedir (Rapaport, 2018).

Mobbing'e maruz kalan bireylerde psikolojik ve fizyolojik sonuçlarını Mikkelsen ve Einarsen, "güneș yanığı" etkisi dereceleri benzetisiyle ilişkilendirerek, mobbing'e mikro düzeyde maruz kişilerin birinci derece yanıklardaki gibi iyileşmesinin daha kolay gerçekleşeceğini, mezzo düzeyde mobbing'in ise ikinci derece yani fazla acı verici ve tedavi gerektiren, en kötü olarak bilinen üçüncü derece yanıklar ise kalıcı hasarlara neden olan derin ve tedavisi uzun sürecek derin yaralara neden olduğu benzetmesini dile getirmiştir (Şen, 2017).

Psikolojik şiddet ve mobbing uygulamaları genel olarak etik dışı davranışlar olarak nitelendirilse de günümüzde artarak devam etmekte ve bireylerin, örgütte yaşadığ 1 sorunları kınama, işten çıkarılma, zaruruiyet gibi nedenlerden dolayı başa çıkma yetilerini kaybederek intihara kadar varan düşünceler taşımalarına sebep olmaktadır.

Hristiyan toplumlarının ortaya çıkmasıyla intihar yasaklanmış ve intiharın bir cinayet olduğu vurgulanmıştır (Durkhe- 
im, 2013). Müslüman toplumlarda da bir başkasının canına kıymak nasıl günah olarak kabul ediliyorsa, bireyin kendi canına kıyması ve yaşamına son vermesi de büyük bir günahtır (Diyanet.gov.tr). Dolasıyla bu durumların yaşanmaması için toplumların çözüm üretmesi önemli bir araştırma konusudur.

\section{PSIKOLOJIK ŞIDDET}

Çalışma ortamında yaşanan şiddet denildiğinde, fiziksel olarak yapılan kişi ya da gruplara karşı yapılan fiziksel güç uygulaması olarak tanımlanmaktadır. Dönemsel olarak günümüzde fiziksel şiddet kadar psikolojik şiddet uygulamalarında iş yeri şiddetinde görülmektedir. İş görenlerin çalışma ortamlarında meydana gelen duygusal taciz, korkutma ve tehdit, yıldırma, alay etme, başka kimselerin yanında küçük düşürme veya aşağılayıcı söz ve davranışlarda bulunma psikolojik şiddet içeren eylemlerdir (Çöl, 2008). Psikolojik şiddet uygulamaları örgütlerin sağlıksız ve huzursuz bir ortama dönüştüren toplumsal ve sosyal bir olgu olarak bilinmektedir. Çünkü psikolojik şiddet toplumun ahlaki değerlerini önemli ölçüde yıpratan ve zedeleyen kötü bir vasıta olmaktadır (Akbaş ve Karcıoğlu, 2010).

\section{MOBBING}

Literatürde farklı kavramlarla açıklansa da mobbing, çalışma ortamında iş görene yapılan duygusal baskıyla birlikte yıldırma politikaları uygulanmasıdır (Mimaroğlu ve Özgen, 2008). İngilizce kelime anlamı yıldırma (mobbing), Mob kökü, kanunsuz bir şekilde şiddet uygulayan topluluk veya çete olarak adlandırılmıştır. Bu kavram 1984 yılında Heinz Leymann'ın bir raporuyla ortaya çıkarak, 1993 yılında ise "İşyerinde Kişilerin Mağdur Edilmesi" kanunuyla İsveç'te yasalaşmıştır (psikiyatri.org.tr). İş yaşamında mobbing, kişilere amirleri, eşit düzeyde çallşanlar ya da astları tarafından sistematik bir şekilde uygulanan çeşitli kötü muamele, şiddet ve tehdit, rencide edici davranışları ifade eden kavramdır (Tınaz, 2006). Mobbing gelişmiş ülkelerde çok sık yaşanan ve hukuki davalara konu olan uygulamalardır. Türkiye'de Avrupa ülkelerine nazaran yeni bir terim olan mobbing örgütler açısından incelendiğinde sosyal bir tehdit ve önemli bir sorun olduğu düşünülmektedir (Akbaş ve Karcıoğlu, 2010).

Tablo 1. Mobbing'in Sonuçları

\begin{tabular}{|l|l|}
\hline Etki Alanı & Sonuç \\
\hline Mağdur & $\begin{array}{l}\text { Aşırı stres sonucu psikolojik ve fiziksel rahatsızlıklar ve intihar } \\
\text { ile sonuçlanabilen travmalar }\end{array}$ \\
\hline Aileler & $\begin{array}{l}\text { Mutsuz ebeveynler ve çarpık yetişen çocuklar, artan boşan- } \\
\text { malar }\end{array}$ \\
\hline Örgütler & $\begin{array}{l}\text { Anlaşmazlıklar, hastalıklı şirket kültürü, düşük moral ve kısıt- } \\
\text { lanmış yaratıcılık }\end{array}$ \\
\hline Toplum & Mutsuz bireyler ve politik kaygısızlık \\
\hline
\end{tabular}

Kaynak: Mobbing'in Sonuçları.Davenpord vd. (2003: 146). (Mizrahi, 2013).

Çalışma Hayatında Mobbing ile Mücadele Yöntemleri. Sosyal ve Beşeri Bilimler Dergisi

\section{TRAVMA VE INTIHAR}

Bireylerin bedensel ve ruhsal benliğine her türlü zarar veren, kişinin başa çıkma yeteneğini aşan deneyimdir. Benlik içsel ya da dişsal olarak çeşitli uyaranlara maruz kalarak etkisiz hale gelen baş etme sonrası, stres ve kişilik bozukluğu, depresyon, madde kullanım gibi travma sonrası sorunlar ve fiziksel hastalıklarla karşılaşmaktadır (Çam vd, 2016).

Emile Durkheim (2013), intiharı, " Kurbanın kendisi tarafından gerçekleştirilmiş, olumlu ya da olumsuz bir edimin doğrudan ya da dolaylı sonucu olan her ölüm olayıdır" tanımıyla açıllamıştır. Bütün depresyon türlerinde bireyin kendi yaşamını sonlandırması riski yani intihar etkendir (Butcher, Mineka ve Hooley, 2013).

\section{ÇALIŞANLARIN IŞYERLERINDE YAŞADIĞI MOBBING VE PSIKOLOJIK ŞIDDET}

Endüstri Psikolog Dr. Heinz Leyman 45 ayrı mobbing uygulaması özelliğini 5 gruba ayırmıștır (Soysal, 2015);

Tablo 2. Mobbing Uygulaması Özellikleri

\begin{tabular}{|l|l|l|}
\hline $\begin{array}{l}\text { 1 GRUP } \\
\text { Kendini göstermeyi ve } \\
\text { iletişim oluşumunu } \\
\text { engellemek: }\end{array}$ & $\begin{array}{l}\text { 2. GRUP } \\
\text { Sosyal ilişkilere } \\
\text { saldırılar: }\end{array}$ & $\begin{array}{l}\text { 3. GRUP } \\
\text { İtibarınıza saldıılar: }\end{array}$ \\
\hline $\begin{array}{l}\text { Üstler tarafından kısıtlan- } \\
\text { mak, azarlanmak, sürekli } \\
\text { eleştirilmek }\end{array}$ & $\begin{array}{l}\text { Çevrenizdekiler sizinle } \\
\text { konuşmaz, sizin baş- } \\
\text { kalarıyla konuşmanız } \\
\text { engellenir. }\end{array}$ & $\begin{array}{l}\text { İnsanlar arkanızdan } \\
\text { kötü konuşur, } \\
\text { asılsız söylentilerle } \\
\text { gülünç duruma } \\
\text { düşürülürsünüz. }\end{array}$ \\
\hline $\begin{array}{l}\text { 4. GRUP } \\
\text { Kişinin yaşam kalitesi } \\
\text { ve mesleki durumuna } \\
\text { saldırışlar: }\end{array}$ & $\begin{array}{l}\text { K.GRUP } \\
\text { Kişinin sağlığına doğ- } \\
\text { rudan saldırılar: }\end{array}$ & \\
\hline $\begin{array}{l}\text { Sizin için özel görevler } \\
\text { verilmez. Iş̧iniz sürekli } \\
\text { değiştirilir. }\end{array}$ & $\begin{array}{l}\text { Fiziksel olarak ağır } \\
\text { işler verilir. Fiziksel } \\
\text { şiddet tehdidi yapılır. }\end{array}$ & \\
\hline
\end{tabular}

Belirli bir kararın yada vakanın etik bir uygulama olup olamadığı davranışın ahlaki standartlarla uyumu ve bireyin kendisi ve diğerleri için sonuçlarına bakılmalıdır. Kriterler değerlendirilmesi sonuca giden yöntemlerin ne ölçüde mubah olduğudur. Davranış değerlendirilmesinde kullanılan ahlaki standartlar, toplumun asıl yasalarının ihlali, diğerlerinin haklarını kullanmasına engel teşkil etmesi, onların sağlık ve yaşamlarını tehlikeye sokmak ya da kişisel fayda ve çıkarlar için insanları aldatma ve kullanma durumu söz konusudur. Var olan bir bilgiyi çarpıtarak aktarmak, kendisinin yapmış olduğu hataları başkasının üzerine atmak, diğerlerini incitecek ve rencide edecek sorumsuz davranışlar batılı devletlerde etik dışı davranışlar olarak nitelendirilmektedir (Yukl, 2018). Örgütlerde bireylerin şahsi çıkarları doğrultusunda diğer çalışanları huzursuz ve mutsuz edecek davranışlar sergilemesi etik dışı sayılarak hiçbir toplumda kabul görmemektedir.

Mobbing'e maruz kalan iş gören hayatının her alanında kendisine olan güvenini kaybeder. Bunun sonuçları iş, aile sosyal ilişkilerine yansır. Kurbanlar şaşkınlık, beceriksiz- 
lik, korku, utanma, çekinme gibi duygular taşır. Zamanla aile ve sosyal çevresinden uzaklaşır. Mobbing sonucu sadece kurbanın kendisi değil tüm ailesi ve yakınları da zarar görmüș olur. Bireyler, mobbing sonuçlarını bir bütün olarak yaşadığı takdirde, akıl, beden ve ruh sağlığı da zarar görür. Yoğun olarak yaşadığı stres sonucu panik atak ve depresyon ve bazı durumlarda ise intihara teşebbüs görülmektedir (Gökçe, 2010). Mobbing'ten etkilenen bireyler işlerini yapamaz duruma gelerek çalışma yaşamına kolay uyum sağlayamazlar. Bireyler dehşet içinde bir haldedir ve şiddetli depresyon, panik atak gibi hastalıklar ve kaza ve intihar girişimleri gözlenmektedir (Yalçın, 2006).

Bireylerde özellikle de sağlık çalışanlarının işyerlerinde yaşadıkları mobbing, depresif semptomların görülmesinde etkili olmaktadır. Bu durumda bireylerin yaşam kalitesini olumsuz yönde etkiler. Bireysel ve sağllk sektörü açısından değerlendirildiğinde, çalışma performans azlığı, isteksizlik gibi sonuçlar yaşanmaktadır (Yavuzer, Çivilidağ, 2014).

\section{ÇALIŞANLARA UYGULANAN MOBBING, PSIKOLOJIK ŞIDDET VE INTIHAR EĞILIMLERININ SOSYO EKONOMIK ETKILERI}

Verimlilik, bireylerin huzurlu, refah ve daha konforlu bir yaşam seviyesine ulaştırmak için bir araçtır. Verimlilik üretim süreçlerine pozitif değer katar. Verimlilik sosyo-ekonomik sorunlarımızın teşhisini, çözümünü ve uygulamasını mümkün kılmaktadır. Dolayısıyla verimlilik sadece üretim değil bir yaşam tarzı olarak algılanmalıdır (Demirci, 2005).

Mobbing ve psikolojik şiddetin topluma getirdiği politik ve mali etkileri aşağıdaki tabloda yer almaktadır (Davenport vd, 2003: Aktaran: Yeniçeri, 2006):

Çalışanlara uygulanan zorbalık ve taciz olguları, tablo 1'de görülen literatür araştırmalarında çeşitli sosyo-ekonomik yönleriyle değerlendirildiğinde hem mikro bireysel hem de organizasyonel seviyelerde bir dizi sosyal veya ekonomik sorunlara neden olmaktadır (Vveinhardt vd., 2018). Kaybedilen verimsiz çalışma saatlerinin çoğu, psikososyal faktörlerden kaynaklandığından çalışma ortamını iyileştirmeye yönelik yatırımlar etkili ve karlı ekonomik karar alma olarak değerlendirilmektedir (Rezagholi, 2016).
Tablo: 3. Politik ve Parasal Maliyetler

\begin{tabular}{|c|c|c|}
\hline $\begin{array}{l}\text { Etki } \\
\text { Alanı }\end{array}$ & Psikolojik Maliyetler & Parasal Maliyetler \\
\hline Bireyler & $\begin{array}{l}\text { Stres } \\
\text { Duygusal, fiziksel rahatsız- } \\
\text { lıklar } \\
\text { Kazalar } \\
\text { Sakatlıklar } \\
\text { Ayrılık acıları } \\
\text { Mesleki kimlik kaybı } \\
\text { Arkadaşlıkların kaybı } \\
\text { Intihar/Cinayet }\end{array}$ & $\begin{array}{l}\text { Ilaçlar ayakta tedavi } \\
\text { Terapi } \\
\text { Doktor faturaları } \\
\text { Hastane faturaları } \\
\text { Kaza masrafları } \\
\text { Sigorta primleri } \\
\text { Avukat ücretleri } \\
\text { Isşizlik } \\
\text { Kapasite altında çalışması } \\
\text { Iş araması }\end{array}$ \\
\hline Aileler & $\begin{array}{l}\text { Çaresiz kalma acısı } \\
\text { Kavga ve çatışmalar } \\
\text { Ayrılık veya boşanma acısı } \\
\text { Çocuklara etkileri } \\
\text { Ayrılma, boşanma masrafları }\end{array}$ & $\begin{array}{l}\text { Ailenin gelir kaybı, } \\
\text { Ayrılma ve Boşanma masrafları, } \\
\text { Terapi. }\end{array}$ \\
\hline $\begin{array}{l}\text { Kuru- } \\
\text { luşlar }\end{array}$ & $\begin{array}{l}\text { Anlaşmazlıklar } \\
\text { Hastalıklı şirket kültürü } \\
\text { Düşük moral } \\
\text { Kısıtlanmış yaratıcılık }\end{array}$ & $\begin{array}{l}\text { Hastalık izinlerinin artması } \\
\text { Yükssek personel hareketi } \\
\text { maliyeti } \\
\text { Düšük verim } \\
\text { Düşük iş kalitesi } \\
\text { Uzmanlık kaybı } \\
\text { Çalışanlara tazminat ödemeleri } \\
\text { Isşizlik maliyetleri } \\
\text { Yasal işlem/dava masrafları } \\
\text { Erken emeklilik } \\
\text { Yükselen personel yönetim } \\
\text { maliyetleri }\end{array}$ \\
\hline $\begin{array}{l}\text { Top- } \\
\text { lum, } \\
\text { Toplu- } \\
\text { luk }\end{array}$ & $\begin{array}{l}\text { Mutsuz bireyler } \\
\text { Kaygilar }\end{array}$ & $\begin{array}{l}\text { Sağıık masrafları } \\
\text { Sigorta masrafları } \\
\text { İşsizlik veya kapasite altı } \\
\text { çalıştırmaktan doğan vergi } \\
\text { kayıpları, } \\
\text { Kamu yardım programlarına } \\
\text { talebin artması, } \\
\text { Zihinsel sağlık programlarına } \\
\text { talebin artması, } \\
\text { Malulen emeklilik taleplerinin } \\
\text { artması. }\end{array}$ \\
\hline
\end{tabular}

\section{SONUÇ}

Rekabetçi küreselleşme, ülkelerdeki ekonomik dalgalanmalar kurumları ve tüm çalışma dünyasını önemli ölçüde etkilemektedir. Genel olarak ekonomik temelli yaşananlar sorunlar, çalışanların iş yerlerinde değişimler ve bir takım baskı ortamlarının oluşmasına neden olmaktadır. Bunlar, mesai saatlerinde artış, kısıntılı dinlenme molaları, performans beklentilerinin yanında, çalışanlar arasında yaşanan rakip çekişmeleri, üst yönetimin ayrımcıllk yapması ve bütün bunları psikolojik şiddet ve mobbing uygulamasıyla çalışanların bedensel ve ruhsal sağlıkların-

Tablo: 4. Zorbalık ve Tacizden Kaynaklanan Zararların Hesaplanmasında Önemli Değişkenler

\begin{tabular}{|l|l|l|}
\hline Değişkenler & Kayıp Kaynaklar & Araştırma \\
\hline Çalışanların kayıpları & $\begin{array}{l}\text { Kuruluşa bağlııı düşüyor, çalışanlar, psiko-sos- } \\
\text { yal baskılar, şiddet ve çevredeki insanlardan çok } \\
\text { az destek almaları nedeniyle işlerini bırakma } \\
\text { eğilimindedir. }\end{array}$ & $\begin{array}{l}\text { Vartia (2001), Figueiredo-Ferraz ve ark. (2012), } \\
\text { McTernan ve ark. (2013), Middlemiss (2017) vd. }\end{array}$ \\
\hline Verimlilikte düşüş & $\begin{array}{l}\text { Iş performansının kötüleştirilmesi, verimliliğin } \\
\text { düşmesi, şirket çalışanlarının personel devir } \\
\text { hızı. }\end{array}$ & $\begin{array}{l}\text { Giga ve ark (2008), Okechukwu vd (2014), } \\
\text { Chandrasiri, 2017; vd. }\end{array}$ \\
\hline Çalışanların hastalık oranı & $\begin{array}{l}\text { Psikolojik ve fiziksel rahatsızlık, çeşitli sağlık } \\
\text { sorunları, çeşitli sürelerde hastalık izinlerinin } \\
\text { belirlenmesi ve tıbbi maliyetler }\end{array}$ & $\begin{array}{l}\text { Carnero, Martinez (2005), Pate Beaumont } \\
\text { (2010), Taşpınar ve ark (2013), Okechukwu ve } \\
\text { ark (2014), vb. }\end{array}$ \\
\hline Tazminatlar, para cezaları, yasal masraflar & $\begin{array}{l}\text { Iş̧verene çalışanların korunması için uygulanan } \\
\text { yasal işlemlerin ihlali nedeniyle para cezası, } \\
\text { mağdurlara tazminat ödenmesi }\end{array}$ & $\begin{array}{l}\text { Sheehan (1999), Fattori ve ark. (2015), Middle- } \\
\text { miss (2017) vb. }\end{array}$ \\
\hline
\end{tabular}

Kaynak: (Vveinhardt, Fominiene ve Ufartiene, 2018) 
da önemli tahripler yaşanmasına neden olmaktadır. İşyerinde yaşanan mobbing ve zorbalıklar intihar fikrinin de öncüsü olabilmektedir (Alavi, Teshetukha, Prost, Antoniak, Patel, Sajid ve Groll, 2017).

Bireylerin zamanlarının önemli kısmını geçirdikleri işyerlerinde intiharı önleme faaliyetlerinden yararlanılabilir. Risk altındaki çalışanlar tespit edilerek destek hizmetleri sağlanması önemlidir (Peterson, Stone vd, 2018).

Mobbing iş etkinliğine etki eden bir maliyet faktörü olarak görülmelidir. Bu nedenle de örgütsel bağlamda, mobbing önlemek amaçlı sistemler oluşturmak personel gelişimi yöneticilerinin önemli sorumluluğudur (Niedl, 1996).

İş yerlerinde yaşanan mobbing, psikolojik şiddet gibi baskı ortamlarında çalışmak zorunda kalarak fiziksel ve ruhsal hastalıklar yaşamalarına neden olan çalışanların, sağlık amaçlı izin almaları, iş yeri verimsizliği ve düzensiz çalışma sürelerine ve şirketlerde mali yüke sebep olmaktadır. Aile yaşantısına yansıyan sorunlar, toplumda da olumsuz ve huzursuzluk yaratma faktörüdür.

Her kurumda çalışanların sosyal ve psikolojik destek alacağı birimler oluşturup, kurumlarda yaşanan şiddet uygulamalarına maruz kalan personele destek hizmetlerinin sağlanması yarar sağlayacaktır. Bu birimlerde yapılacak olan işyeri uyumu, zihinsel ve fiziksel tedavi yöntemlerinin etkili olacağı düşünülmektedir. Çalışanlarının tükenmişliklerinin nedeni olan, uzun mesai saatlerinin düzenli hale getirilerek çalışanların sosyal etkileşim faaliyetlerine teşviki de olumlu etkiler yaratacağının değerlendirilmesi önemlidir.

\section{KAYNAKÇA}

Akbaş, S. , Karcıoğlu, F. (2010). İşyerinde Psikolojik Şiddet ve iş̧ Tatmini İlişkisi. Atatürk Üniversitesi İktisadi ve İdari Ilimler Dergisi. 24; 3

Alavi, N. ,Reshetukha, T. , Prost, E. , Antoniak, K. , Patel, C. , SAjid, S. , Groll, D. (2017). Relationship between bullying and suicidal behaviour in youth presenting to the emergency department. J. Can Acad Child Adolesc Psychiatry. 26 (2): 70-77.

Butcher, J. N. ,Mineka, S. , Hooley, J. M (2013). Anormal Psikoloji. (Çeviren, Gündüz, O.). İstanbul: Kaknüs Yayınları.

Çam, O., Büyükbayram, A., Turgut, E. Ö. (2016). Travma Sonrasında Ruh Sağlığı ve Hastalıkları Hemşireliği Yaklaşımı.Anadolu Hemşirelik ve Sağıık Bilimleri Dergisi. 19; 3.

Çöl, Ö, S. (2008). İşyerinde Psikolojik Şiddet: Hastane Çalışanları Üzerine Bir Araştırma. Çalışma ve Toplum Dergisi 2008/4.

Demirci, F. S. (2005). Verimlilik bilinci ve Kültürünün Işlevselliği, Değişime Katkısı. Verimlilik Dergisi. 2005/3

Din İşleri Yüksek Kurulu Başkanlığı. https://kurul.diyanet.gov.tr/

Durkheim, E. (2013). İntihar. (Çeviren, İlkgelen.Z. Z.). Pozitif Yayıncilık.

Memduhoğlu, H. B. ve Yılmaz, K. (2010). Yönetimde Yeni Yaklaşımlar İçinde. Örgütlerde Yıldırma Mobbing. Gökçe, A. T. Ankara: Pegem Akademi.
Mimaroğlu, H. , Özgen, H. (2008). Örgütlerde Güncel Bir Sorun: Mobbing. SÜ iiBF Sosyal ve Ekonomik Araştırmalar Dergisi.

Mizrahi, R.(2013). Çalışma Hayatında Mobbing ile Mücadele Yöntemleri. Sosyal ve Beşeri Bilimler Dergisi. 5 (2).

Niedl, K. (1996). Mobbing and well-being: Economic and personnel development implications. Europan Journal of Work and Organizational Psychology, 5 (2), 239-249.

Psikiyatri.org.tr: Yıldırma (Mobbing). 10 Ocak Tarihinde http:// www.psikiyatri.org.tr/halka-yonelik/15/yildirma-mobbing adresinden ulaşılmıştır.

Rapaport, L. (2018). Suicide rate rising among U. S. workers. 25 Mart 2019 Tarihinde https://www.reuters.com/article/us-health-suicide-occupation/suicide-rate-rising-among-u-s-workers-idUSKCN1NQ2M6 adresinden alınmıştır.

Rezagholi, M. (2016). Differential Socio-Economic Effects of Work Environmental Risk Factors. Journal of Health \& Medical Economics.

Soysal, Ö. N.(2015). İş Yerinizde Mobbing Yaşıyor musunuz? Erişim Tarihi: 29 Şubat 2019 Tarihinde https://www.kariyer. net/ik-blog/is-yerinizde-mobbing-yasiyor-musunuz/adresinden alınmıştır.

Peterson, C. , Stone, M. D. , Marsh, M. S. , Schumacher, P.K, Tiesman, M. H. , Mclntosh, L. W. , Lokey, N. C. , Trudeau, T. A. , Bartholow, B. , Luo, F. (2018). Suicide rates by major occupational group- 17 states, 2012 and 2015. Centers for Disease Control and Prevention. Weekly/November 16, 2018/ 67(45); 1253-1260.

Şen, N. (2017). İş Hayatında Psikolojik Şiddet (Mobbing): Trabzon Örneği. İmgelem 1 (1) 135-151.

Tınaz, P. (2006). İş Yerinde Psikolojik Taciz Mobbing. Çalışma ve Toplum Dergisi 2006/4

Vveinhardt, J. ,Fominiene, B. V. , ve Ufartiene, J. , L. (2018). Bullying and Harassment as Antisocial Behaviours: Socio- Economic Aspects of Their Impact Assessment. Inzinerine Ekonomika- Engineering Economics. 29 (5). 548- 558

Yalçın, i. (2006). Baskıyı yönetim aracı olarak kullanan yöneticilerin çalışanlar üzerinde yarattığı etkiler. Yönetimde yeni yaklaşımlar içinde. (Yeniçeri, Ö.) 2006. İstanbul: IQ Kültür Sanat Yayıncilık.

Yavuzer, Y. ve Çivilidağ, A. (2014). Mediator role of depression on the relationship between mobbing and life satisfaction of health professionals. Thejournal of psychiatry and neurological sciences. 27. 115-125.

Yeniçeri, Ö. (2006). Yönetimde yeni yaklaşımlar. İstanbul: IQ Kültür sanat yayıncilık.

Yukl, G. (2018). Örgütlerde Liderlik. (Çeviren, Çetin, Ş. ve Baltacı, R.), Ankara: Nobel Akademik Yayıncılık. 8. Basımdan çeviri. 